\title{
Effect of Processing of Horsegram (Macrotyloma uniflorum) on the Glycemic Index Value of Normal and Diabetic Subjects
}

\section{Luna Dutta Baruah ${ }^{1 *}$ and Asha Arya ${ }^{2}$}

${ }^{1}$ Assistant Professor, Department of Food Science and Nutrition, College of Community Science, Assam Agricultural University, Assam, India

${ }^{2}$ Professor (Retd.), Department of Foods and Nutrition, College of Home Science, VNMKV, Maharashtra, India

*Corresponding Author: Luna Dutta Baruah, Assistant Professor, Department of Food Science and Nutrition, College of Community Science, Assam Agricultural University, Assam, India.
Received: April 19, 2021

Published: June 03, 2021

(C) All rights are reserved by Luna Dutta

Baruah and Asha Arya.

\begin{abstract}
Horse gram (Macrotyloma uniflorum, earlier Dolichos biflorus. $L$ ) is an underutilized legumes which has the potential to be used as a low glycemic index (GI) food due to their slow rate of starch digestion. It is reported as an excellent source of protein, dietary fibre, micronutrients, phytochemicals with low fat content and relatively high antinutrient factors. Processing of pulses helps in reducing the antinutritional content thereby increasing the availability of nutrients and digestibility of pulses. Hence, this study was conducted to determine the effect of soaking, roasting, and germination of horsegram in different product forms and its impact on the blood glucose and glycemic index of normal and diabetic subjects. Blood glucose response and glycemic index was recorded by using standard methods. Results indicated that horse gram sprouts (germinated) was found to have significantly low glycemic index value in both normal and diabetic subjects ( $60.59 \pm 3.66$ and $12.49 \pm 0.58$, respectively), than horse gram curry (soaking) ( $66.8 \pm 3.58$ and $26.83 \pm 1.02$, respectively) and horse gram paratha (roasting) (84.12 \pm 1.95 and $51.49 \pm 0.73$, respectively), in both normal and diabetic subjects, respectively. Germinated horse gram as well as horse gram curry (soaking) exhibited glycemic index value less than 30 in diabetic subjects as compared to normal subjects, hence horsegram may be incorporated in the diet and recommended for the dietary management of diabetes, thereby addressing nutrition security in terms of non communicable diseases.
\end{abstract}

Keywords: Horse Gram; Underutilized Legume; Glycemic Index; Diabetic Diet

\section{Introduction}

Underutilized legumes are considered important group of crops have great significance in sustainable agriculture and nutritional security especially in developing countries due to its ever increasing demand for finding alternate vegetable protein sources. Horsegram [Macrotyloma uniflorum (L.) Verdc] is an underutilized indigenous but highly nutritious pulse crop having ethno-medicinal values is mostly consumed only by the farming communities and low-income groups and has great potential for providing food and nutrition security [1]. It is a leguminous crop with high nutritional value in terms of protein, carbohydrates, dietary fibre, vitamins like thiamine, riboflavin and niacin and most of the minerals like calcium, phosphorous, molybdenum, zinc, iron and various types of phytochemicals and low fat [2]. It is a low cost pulse crop which has the potential to be used in various formulations due to its ac- 
ceptable cooking quality [3]. Legumes in particular are considered as low glycemic index (GI) foods as they have beneficial effects in the management of diabetes (Jenkins., et al. 1988). Reducing the glycaemic index of carbohydrate rich foods in diet may in decreasing the metabolic risk of various non-communicable diseases like obesity, cardiovasular diseases and diabetes [4].

Glycemic index is the extent of rise in blood sugar in response to a food in equivalent amount of glucose which is calculated by studying the glycemic response to $50 \mathrm{~g}$ carbohydrates of a test food as a percentage of a standard meal of $50 \mathrm{~g}$ carbohydrate (glucose) [5]. Legumes can significantly reduce blood glucose, insulin, serum cholesterol and low density lipoprotein (LDL) cholesterol due to high total dietary fibers, soluble fiber, amylose, anti-nutrients and slow digestibility of starch in legumes. Slow rate of starch digestion of legumes is however, considered the most important determinant of low glucose and insulin response to diabetes [6]. The glycaemic index (GI) is an important index of food quality which is used to compare the hyperglycaemic effect of a tested meal with pure glucose [7].

According to the International Diabetes Federation (IDF), 463 million people have diabetes in the world out of which $8.9 \%$ (77 million) belong to India [8]. A diet containing high dietary fiber with resistant starch can help control blood sugar and complications in the management of diabetes by reducing postprandial glucose levels [9].

The aim of the present study was to determine the effect of different processing methods like roasting, soaking and germination of horsegram on the glycemic index of horsegram recipes on normal and diabetic subjects.

\section{Materials and Methods}

Preparation of samples

Locally available variety of horsegram (Macrotyloma uniflorum) was selected for this study. The seeds were sorted and cleaned for further use. The cleaned and dried horse gram seeds were ground to pass through a fine mesh $(0.5 \mathrm{~mm})$ for obtaining horsegram flour (for cheela). For the preparation of horsegram curry and horsegram sprouts, the seeds were soaked in filtered water (1:10; seeds: water) overnight at room temperature $\left(25 \pm 2{ }^{\circ} \mathrm{C}\right)$. After decanting water, the soaked seeds with water $(1: 5$; seeds: water; $w / v)$ were pressure cooked for 10 minutes for preparation of curry. For the horsegram sprouts the soaked seeds after decanting were kept at ambient temperature and environment for 72 hours till the sprouts were about $1.5 \mathrm{~cm}$. The germinated horsegram was further used for horsegram sprouts.

\section{Preparation of different horsegram products}

Three products of horse gram namely, horse gram cheela, horse gram curry and horse gram sprouts was prepared using different treatments and methods of cooking like, roasting, soaking, soaking and dehulling; and germination, respectively. Horse gram cheela was developed by soaking (for removing the hull), roasting and grinding the horsegram into a fine flour, addition of salt, spices and oil. Horse gram curry was prepared by subjecting the horsegram to soaking, addition of salt, spices and oil. For horse gram sprouts, horse gram was soaked and germinated for 72 hours and was served with seasoning of salt and spices.

\section{Determination of glycemic index}

Blood glucose response technique was employed to evaluate the glycemic index of each developed test food. Ten normal and ten diabetic subjects between age 40-60 years having no infection, gastrointestinal disorders, food allergies and those willing to serve as experimental subjects were selected for the experiment. Subjects were selected using prepared questionnaire regarding, age, sex, duration of diabetes, occupation, income, education, family history, present complaints, awareness, exercise pattern and food consumption pattern. A weighed amount of test food providing $50 \mathrm{~g}$ of carbohydrate were served to the subjects in post-absorptive condition after a 12 hour overnight fast. The selected subjects were allowed to consume the test food within 15 minutes. Finger prick samples of blood were collected with lancets at $0,30,60,90$, and 120 minutes. Blood glucose content was estimated using glucometer. Blood glucose response for the developed test food was calculated from the food tolerance curve using blood glucose tolerance curve and food tolerance curve. The post-prandial blood glucose incremental area was calculated by measuring incremental area on graph paper above fasting level. The glycemic index of the test food was calculated using the formula given by Wolever., et al. 1991 [5]:

Incremental area under two hours blood glucose curve for test food Glycemic index $=$

Incremental area under two hours blood glucose curve for $50 \mathrm{~g} / 25 \mathrm{~g}$ of glucose

Citation: Luna Dutta Baruah and Asha Arya. "Effect of Processing of Horsegram (Macrotyloma uniflorum) on the Glycemic Index Value of Normal and Diabetic Subjects". Acta Scientific Pharmaceutical Sciences 5.7 (2021): 02-07. 


\section{Statistical analysis}

Statistical analysis of data was done by ANOVA to determine the significant differences between the samples for different processing techniques of horsegram like roasting, soaking and germination, blood glucose response and glycemic index among the normal and diabetic subjects at $95 \%$ confidence.

\section{Results and Discussion}

Blood glucose response values for $50 \mathrm{~g}$ glucose in selected normal and diabetic subjects

All the selected normal and diabetic subjects were provided with $25 \mathrm{~g} / 50 \mathrm{~g}$ of glucose to find out the blood glucose response (Table 1). The mean blood glucose response of normal subjects for
$50 \mathrm{~g}$ of glucose at $0 \mathrm{~min}, 30 \mathrm{~min}, 60 \mathrm{~min}, 90 \mathrm{~min}$ and $120 \mathrm{~min}$ was $95.53 \pm 10.89,165.42 \pm 9.84,198.71 \pm 8.31,148.8 \pm 10.32$ and 97.8 \pm 11.55 , respectively, while the respective values for $50 \mathrm{~g}$ of glucose for diabetics were $184.62 \pm 4.00,286.14 \pm 10.51,274.78 \pm 13.44$, $238.19 \pm 10.61$ and $205.29 \pm 13.38$, respectively. The glucose response at $0 \mathrm{~min}, 30 \mathrm{~min}, 60 \mathrm{~min}, 90 \mathrm{~min}$ and $120 \mathrm{~min}$ by normal and diabetics after the intake of glucose was studied. The blood glucose response was at the highest peak at 1 hour in normal subjects and for diabetic it was found highest at half an hour.

Blood glucose response and glycemic index values of different horse gram products in selected normal subjects

The glycemic index (GI) is a value of the effect of the consumption of certain food on 2 hrs postprandial blood glucose response

\begin{tabular}{|l|c|c|c|c|c|}
\hline \multirow{2}{*}{ Subjects } & \multicolumn{5}{|c|}{ Blood glucose response values (50mg/100ml) } \\
\cline { 2 - 6 } & $\mathbf{0 ~} \mathbf{~ m i n}$ & $\mathbf{3 0} \mathbf{~}$ in & $\mathbf{6 0} \mathbf{~} \mathbf{m}$ & $\mathbf{9 0} \mathbf{~ m i n}$ & $\mathbf{1 2 0} \mathbf{~ m i n}$ \\
\hline Normal & $95.53 \pm 10.89^{\mathrm{b}}$ & $165.42 \pm 9.84^{\mathrm{b}}$ & $198.71 \pm 8.31^{\mathrm{b}}$ & $148.32 \pm 10.32^{\mathrm{b}}$ & $97.8 \pm 11.55^{\mathrm{b}}$ \\
\hline Diabetic & $184.62 \pm 4.00^{\mathrm{a}}$ & $286.14 \pm 10.51^{\mathrm{a}}$ & $274.78 \pm 13.44^{\mathrm{a}}$ & $238.19 \pm 10.61^{\mathrm{a}}$ & $205.29 \pm 13.38^{\mathrm{a}}$ \\
\hline
\end{tabular}

Table 1: Blood glucose response values $(\mathrm{mg} / \mathrm{dL})($ mean $\pm \mathrm{SE})$ for $50 \mathrm{~g}$ of glucose in selected normal and diabetic subjects $(\mathrm{n}=20)$. Data presented as Mean \pm SE $(n=10)$. Mean values in a column superscripted by different letters are significantly different at $\mathrm{p}<0.05$.

with respect to an equivalent carbohydrate portion of reference (glucose). GI is ranked on a scale from 0 to 100 , where foods are classified as high GI, moderate GI, and low GI if GI is $\geq 70,56$ - 69 and $\leq 55$, respectively (5). It was evident from the result (Table 2) that the blood glucose response of the selected normal subjects was at the highest peak at $30 \mathrm{~min}$ following the ingestion of horsegram cheela $(142.6 \pm 2.34)$ and horsegram curry $(128.86 \pm 4.14)$ while horsegram sprouts $(119.38 \pm 4.68)$ exhibited the highest blood glucose response value at $60 \mathrm{~min}$, respectively. The level of blood glucose was found to decline gradually. The blood glucose response values at $120 \mathrm{~min}$ for the selected horsegram products were plotted on the graph paper and incremental area was calculated above the fasting level. It was inferred that horsegram sprouts had low incremental area followed by horsegram curry and horse gram cheela. The obtained values of incremental area of the recipes were further used to calculate the glycemic index of the selected normal subjects.

\begin{tabular}{|l|c|c|c|c|c|}
\hline \multirow{2}{*}{ Name of product } & \multicolumn{5}{|c|}{ Blood glucose response values (mg/dL) } \\
\cline { 2 - 7 } & $\mathbf{0 ~} \mathbf{~ m i n}$ & $\mathbf{3 0} \mathbf{~ m i n}$ & $\mathbf{6 0} \mathbf{~ m i n}$ & $\mathbf{9 0} \mathbf{~ m i n}$ & $\mathbf{1 2 0} \mathbf{~ m i n}$ \\
\hline Horsegram cheela & $98.34 \pm 2.89^{\mathrm{c}}$ & $142.6 \pm 2.34^{\mathrm{c}}$ & $126.6 \pm 1.54^{\mathrm{c}}$ & $118.56 \pm 3.57^{\mathrm{c}}$ & $95.6 \pm 3.09^{\mathrm{c}}$ \\
\hline Horsegram curry & $97.63 \pm 4.32^{\mathrm{b}}$ & $128.86 \pm 4.14^{\mathrm{b}}$ & $106.32 \pm 7.39^{\mathrm{a}}$ & $98.84 \pm 3.22^{\mathrm{a}}$ & $91.26 \pm 8.98^{\mathrm{b}}$ \\
\hline Horsegram sprouts & $89.54 \pm 2.82^{\mathrm{a}}$ & $108.42 \pm 5.80^{\mathrm{a}}$ & $119.38 \pm 4.68^{\mathrm{b}}$ & $105.53 \pm 2.38^{\mathrm{b}}$ & $82.6 \pm 2.85^{\mathrm{a}}$ \\
\hline
\end{tabular}

Table 2: Blood glucose response values $(\mathrm{mg} / \mathrm{dL})$ of horse gram products in selected normal subjects $(\mathrm{n}=10)$. Data presented as Mean \pm SE $(n=10)$. Mean values in a column superscripted by different letters are significantly different at $p<0.05$. 
Blood glucose response and glycemic index values of different horse gram products in selected diabetic subjects

Blood glucose response for $50 \mathrm{~g}$ of the different horse gram products in the selected diabetic subjects revealed that blood glucose response was at the highest peak at 60 min following the ingestion of horsegram cheela $(182.65 \pm 11.13)$ whereas horsegram curry $(184.62 \pm 11.11)$ exhibited the highest blood glucose response value at $30 \mathrm{~min}$ and horsegram sprouts (159.95 \pm 8.94 ) exhibited the highest blood glucose response value at $60 \mathrm{~min}$, respectively (Table 3).

\begin{tabular}{|c|c|c|c|c|c|}
\hline \multirow{2}{*}{$\begin{array}{c}\text { Name of the } \\
\text { product }\end{array}$} & \multicolumn{5}{|c|}{ Blood glucose response values (mg/dL) } \\
\hline & $0 \mathrm{~min}$ & $30 \mathrm{~min}$ & $60 \mathrm{~min}$ & $90 \mathrm{~min}$ & $120 \mathrm{~min}$ \\
\hline Horsegram cheela & $136.54 \pm 8.39^{\mathrm{a}}$ & $174.3 \pm 9.09^{b}$ & $182.65 \pm 11.13^{c}$ & $165.89 \pm 11.00^{\mathrm{b}}$ & $148.32 \pm 15.70^{b}$ \\
\hline Horsegram curry & $152.28 \pm 6.22^{\mathrm{c}}$ & $184.62 \pm 11.11^{\mathrm{c}}$ & $181.33 \pm 14.74^{b}$ & $172.42 \pm 7.33^{\mathrm{c}}$ & $165.74 \pm 9.29^{c}$ \\
\hline Horsegram sprouts & $149.85 \pm 10.20^{b}$ & $156.54 \pm 9.42^{\mathrm{a}}$ & $159.95 \pm 8.94^{\mathrm{a}}$ & $148.32 \pm 5.85^{\mathrm{a}}$ & $143.75 \pm 10.37^{\mathrm{a}}$ \\
\hline
\end{tabular}

Table 3: Blood glucose response values $(\mathrm{mg} / \mathrm{dL})$ of horse gram recipes in selected diabetic subjects $(\mathrm{n}=10)$. Data presented as Mean \pm SE $(n=10)$. Mean values in a column superscripted by different letters are significantly different at $\mathrm{p}<0.05$.

The mean glycemic index of horsegram cheela, horsegram curry and horsegram sprouts of selected normal subjects were $84.12 \pm 1.95,68.21 \pm 3.58$ and $60.59 \pm 3.66$, respectively. Horsegram sprouts had significantly lowest glycemic index $(\mathrm{p}<0.05)$ followed by horsegram curry whereas horsegram cheela had significantly highest glycemic index value $(\mathrm{p}<0.05)$. Horsegram paratha showed highest glycemic index value which couldbe due to the use of flour for preparation of cheela while for curry and sprouts, whole grain seeds were used (Table 4).

\begin{tabular}{|l|c|c|}
\hline $\begin{array}{c}\text { Name of the } \\
\text { product }\end{array}$ & $\begin{array}{c}\text { Normal } \\
\text { (n= 10) }\end{array}$ & $\begin{array}{c}\text { Diabetic } \\
(\mathbf{n}=\mathbf{1 0})\end{array}$ \\
\hline Horsegram cheela & $84.12 \pm 1.95^{\mathrm{a}}$ & $51.49 \pm 0.73^{\mathrm{a}}$ \\
\hline Horsegram curry & $66.21 \pm 3.58^{\mathrm{b}}$ & $26.83 \pm 1.02^{\mathrm{b}}$ \\
\hline Horsegram sprouts & $60.59 \pm 3.66^{\mathrm{c}}$ & $12.49 \pm 0.58^{\mathrm{c}}$ \\
\hline
\end{tabular}

Table 4: Glycemic index value of different horse gram recipes in selected normal and diabetic subjects.

Data presented as Mean \pm SE $(n=10)$. Mean values in a row superscripted by different letters are significantly different at $\mathrm{p}<0.05$.

The level of blood glucose was found to decline gradually following the peak. Horsegram sprouts showed low incremental area followed by horse gram curry and horse gram cheela. Horsegram sprouts $(12.49 \pm 0.58)$ showed significantly lowest mean value of glycemic index followed by horsegram curry $(26.83 \pm 1.02)$ whereas horsegram cheela (51.49 \pm 0.73 ) had significantly highest value of glycemic index in selected diabetic subjects (Table 4). Horsegram sprouts may thus can be used liberally and horsegram curry may be used moderately in the diet of diabetic subjects as they have significantly low glycemic index value less than 30 .

The present study implicated that horsegram when used in different forms had different effect on the blood glucose release and glycaemic index on both normal and diabetic subjects. Horsegram seed was found to contain high amount of non-digestible carbohydrate, i.e., about $6.38 \%$ total soluble sugars of which $55-65 \%$ constitute raffinose family oligosaccharides (RFO), stachyose and verbascose [10] which could be accounted to the lower release of glucose. However, various studies supported that processing improves the nutritional profile of horsegram after different treatment methods soaking, roasting and sprouting. Research studies also supported that processing of horsegram, such as soaking, cooking and sprouting, altered the levels of oligosaccharides [11]. Khatoon and Prakash (2004) [12] in their study found that horsegram seeds contained high amount of total dietary fibres (28.8\%), mainly as insoluble dietary fibre (IDF) $27.82 \%$ and soluble dietary fibre (SDF) 1.13\% with IDF: SDF 24.6, as compared to horsegram flour, which contained about $16.3 \%$ total dietary fibre $(14.9 \%$ insoluble and $1.4 \%$ soluble and $2.2 \%$ resistant starch) [13]. Thus the comparatively high amount of total dietary fibres in horsegram 
seed used for horsegram curry and horsegram sprouts can be attibuted to the lower release of glucose in horsegram curry and horsegram sprouts as compared to horsegram flour used for horsegram cheela. It was also reported that raw unprocessed horsegram seeds along with the seed coat are concentrated source of antioxidant and consumption of food items prepared with it may have more health benefits for hyperglycaemic individuals than after removing the hull [14]. This lower release of glucose in horsegram curry and horsegram sprouts resulted in the diffences in the lower glycemic index value as compared to horsegram cheela. Horsegram flour used for horsegram cheela which involved simple processing like soaking and roasting could be linked to elimination of the antinutritional content making the product rich source of protein, calcium and dietary fibre [15]. Further, Sreerama., et al. 2012 [13] in their study reported that horsegram flour had favourable functional properties like higher water absorption capacity (148.1 mg\%), emulsion activity $(58.1 \pm 0.5 \%)$ and emulsion stability $(52.0 \pm 1.6 \%)$ due to which it can be used in the preparation and development of various food products. Simple processing like roasting, soaking and germination cause significant reduction in phytic acid content in legumes and also for complete elimination of the toxicity of lectins present in the seedcoats of horsegram [16]. It was also reported that sprouting of horsegram alters its metabolic reaction affecting the bioavailability, palatability and digestibility of essential nutrients and insulinlike proteins are synthesised during the process of germination of seeds and, contributing to the fact that consumption of sprouts may be beneficial for diabetic patients [17]. This fact further supported that glycemic index was found to be significantly low when both the normal and diabetic subjects consumed horsegram sprouts as compared to horsegram curry and horsegram cheela where only soaking and roasting were involved. The seeds and sprouts of horsegram have health promoting effects in addition to its nutritive value which can be used for dietary mangement of diabetes.

\section{Conclusion}

Horsegram may be considered as having potential beneficial effects in the dietary management of diabetes due to its high non-digestible carbohydrate content which cause lower release of glucose into the blood stream. The seeds, sprouts or whole meal of horsegram is used by large populations in rural areas. It is a low cost pulse with high protein and acceptable cooking quality and has the potential to formulate products. It can thus be established that the products developed from horsegram like cheela, curry and sprouts could be successfully used for supplementing the diet with high protein, high dietary insoluble fibre and most of the other nutrients for normal inclusion in the diet. It can be further be successfully utilized in the management of diabetes of the vast population due to its low cost measures and availability for addressing the food and nutrition security of the population.

\section{Bibliography}

1. Bhartiya A., et al. "Nutritional And Remedial Potential of on Underutilized Food Legume Horsegram (Macrotyloma Uniflorum): A Review". The Journal of Animal and Plant Sciences 25.4 (2015): 908-920.

2. Herath HMT., et al. "Horse Gram: an incredible food grain as a potential source of functional and nutritional food ingredient". International Journal of Food Science and Nutrition 5.4 (2020): 93-101.

3. Hiramath J., et al. "Chemical composition and functional properties of some important genotypes of horsegram [Macrotyloma uniflorum (Lam.) Verdc]”. Karnataka Journal of Agricultural Sciences 14.4 (2001): 943-946.

4. Vrolix R., et al. "The metabolic syndrome in relation with the glycaemic index and the glycaemic load". Physiology and Behaviour 90 (2008): 293-299.

5. Wolever TMS., et al. "The glycemic index: methodology and clinical implications". The American Journal of Clinical Nutrition 54.5 (1991): 846-854.

6. Brand JC., et al. "Low Glycemic Index". The American Journal of Clinical Nutrition 42 (1990): 1192.

7. Chlup R., et al. "Determination of glycaemic index of selected foods (white bread and cereal bars) in healthy persons". Biomedical Papers 148 (2004): 17-25.

8. Kannan R. "India is home to 77 million diabetics, second highest in the world". The Hindu (2019).

9. Post RE., et al. "Dietary Fiber for the Treatment of type 2 Diabetes Mellitus: A Meta-Analysis". The Journal of the American Board of Family Medicine 25.1 (2012): 16-23. 
10. Kadam SS and Salunkhe DK. "Nutritional composition, processing, and utilization of horsegram and moth bean". $C R C$ Critical Reviews in Food Science and Nutrition 22 (1985): 1-26.

11. Machaiah JP and MD Pednekar. "Carbohydrate composition of low dose radiation-processed legumes and reduction in flatulence factors". Food Chemistry 79.3 (2002): 293-301.

12. Khatoon N and Prakash J. "Nutritional quality of microwavecooked and pressure cooked legumes". International Journal of Food Sciences and Nutrition 55.6 (2004): 441-448.

13. Sreerama YN., et al. "Nutrients and antinutrients in cowpea and horsegram flours in comparison to chickpea flour: Evaluation of their flour functionality". Food Chemistry 131 (2012): 462-468.

14. Tiwari AK., et al. "Raw horsegram seeds possess more in vitro antihyperglycaemic activities and antioxidant properties than their sprouts". Nutra Foods 12.2 (2013): 47-54.

15. Thirukkumar S and Sindumathi G. "Studies on preparation of processed horse gram (Macrotyloma uniflorum) flour incorporated chappathi". International Journal of Scientific Research 3.3 (2014): 110-111.

16. Khamgaonkar SG., et al. "Processing technologies of Uttarakhand for lesser known crops: An overview". Journal of Academia and Industrial Research (JAIR) 1.8 (2013): 447-452.

17. Pathak M and Martirosyan DM. "Immunodetection and quantification of insulin-like antigens in sprouts: development of an efficient functional food". Functional Foods in Health and Disease 1 (2011): 492-507.

Volume 5 Issue 7 July 2021

(C) All rights are reserved by Luna Dutta Baruah and Asha Arya. 